\title{
Morris Sensitivity Analysis for Hydrothermal Coupling Parameters of Embankment Dam: A Case Study
}

\author{
Jie Ren (D), 1,2 Wenbing Zhang, ${ }^{1,2}$ and Jie Yang ${ }^{1,2}$ \\ ${ }^{1}$ State Key Laboratory of Eco-Hydraulics in Northwest Arid Region of China, Xian University of Technology, \\ Xian 710048, Shaanxi, China \\ ${ }^{2}$ Institute of Water Resources and Hydroelectric Engineering, Xian University of Technology, Xian 710048, China
}

Correspondence should be addressed to Jie Ren; renjie@xaut.edu.cn

Received 5 March 2019; Revised 29 April 2019; Accepted 20 May 2019; Published 9 June 2019

Academic Editor: Andrés Sáez Copyright ( $\odot 2019$ Jie Ren et al. This is an open access article distributed under the Creative Commons Attribution License, which
permits unrestricted use, distribution, and reproduction in any medium, provided the original work is properly cited.

\begin{abstract}
Recently, the use of the temperature tracer method has attracted a great deal of attention to study the dam leakage. Accurate estimation of temperature variations inside the dam is critical, and the task can be achieved by identifying which variables play more important roles in the hydrothermal coupling model (HTCM). In the present study, the HTCM of an embankment dam is defined based on the thermal conductivity model proposed by Lu et al. (2007). The thermal conductivity model needs several input parameters, many of which are usually determined by pedotransfer functions, which may introduce a certain degree of uncertainty. Using the Morris method, the embankment dam of a reservoir, located in Shaanxi province of China, was chosen as the case study to investigate the sensitivity of each parameter of the HTCM on the temperature field of the embankment dam. The sensitivity analysis showed that the hydraulic conductivity $\left(K_{s}\right)$ of HTCM has the highest effect on the dam temperature field. On the other hand, the saturated water content $\left(\theta_{s}\right)$, residual water content $\left(\theta_{r}\right)$, and porosity $(n)$ only slightly influence the temperature estimation of the model. Accordingly, the effects of these three parameters on the heat conduction and the subsequent temperature field of the dam can be neglected. Results of this study showed that the model correction workload can be substantially reduced. Hence, the efficiency of the model correction procedure leads to reasonable selection of decision parameters and can be significantly improved by reducing the number of these parameters for the HTCM of the embankment dam.
\end{abstract}

\section{Introduction}

In normal operating conditions, the temperature of dam foundation and dam body are mainly affected by the seepage conditions. Water movement in the rock-soil medium of the dam can affect its temperature distribution during the time [1]. Consequently, studying the coupled temperature and seepage effects of the embankment dam may provide a theoretical basis to make a correlation between seepage and temperature fields, in order to find the safe states of the seepage [2]. Development of the seepage-heat monitoring technology in embankment dams makes it possible to analyze the seepage field and find the seepage failure points, by monitoring the temperature field. Accordingly, many researchers have tried to develop mathematical models that can reflect the coupled effects of temperature and seepage fields in embankment dams $[1,3-6]$. However, these models show nonlinear behaviors with many affecting parameters that will make the models very complex. Various uncertainty sources, such as the diversification of model parameters scale and systematic errors, increase the resulting uncertainty of these models. Therefore, uncertainty and sensitivity analysis of hydrothermal models are extremely helpful to find the interaction between input parameters of a model as well as their weight and influence on the model results [7]. A quantitative study of the influencing factors of the model can lead engineers to find the dominant affective parameters in the temperature field. As a consequence, results can be estimated with improved accuracy by focusing on the dominant influencing factors and ignoring or reducing the weight of other factors. Hence, simpler models can be proposed with less nonlinearity behaviors and the actual phenomenon can be predicted by use of a more precise numerical model. 
In a sensitivity study, the uncertainty of the input parameters and their influence on the model response are analyzed within a specified design space [8]. Afterward, the sensitivity factor is reduced, and only parameters with high sensitivity factors will be calibrated. Accordingly, the model can be simplified with subsequent improvements in the model calibration accuracy as well as the decision-making time and costs [9]. Sensitivity analysis methods are divided into the local and global techniques. Local methods are usually used to study the influence of a single parameter uncertainty on the system response, while other parameters are fixed [10]. Local sensitivity analysis takes the output variation caused by a single input variable as the sensitivity index. The sensitivity index analysis method, the differential ratio analysis method and the automatic differential method all use the local sensitivity analysis method. [11]. Local methods are based on linear models and if a nonlinear term appears in the model, or if the uncertainty of an input variable affects the output at different orders of magnitude, then the local sensitivity analysis method might lead to incorrect results. In contrast, global sensitivity analysis methods can be used to test the interaction of parameters, and also the simultaneous effects of multiple parameters on the response variable [12]. The multivariate regression method [13], the Sobol sensitivity test method [7], the Fourier amplitude sensitivity test (FAST) [14], and the Morris sensitivity method [15] are some examples of these methods. The Morris method is particularly excellent with respect to the other global methods because it makes it possible to analyze the influence of variations of each parameter and also their mutual effects on the model output [16].

Currently, the Morris sensitivity analysis method is widely employed in various engineering problems. King and Perera [17] performed a case study on the Barwon urban water supply system in Australia and applied the Morris method to investigate the importance of input variables used to estimate the yield of urban water supply systems. Wang et al. [12] used the Morris method to analyze the sensitivity of a salt precipitation model to its input parameters and obtained the main influencing factors in the salt precipitation problem. The Morris method was also used by Garcia Sanchez et al. [18] to analyze and illustrate the potential usefulness of combining first- and second-order sensitivity analyses. They applied this method to a building energy model (ESP-r). Yi et al. [19] used the Morris sensitivity analysis technique and focused on the sample size and factors perturbation ranges to study the sensitivity with regard to different output metrics of the water quality model, and they analyzed the consistency between different sensitivity scenarios.

Sensitivity analysis methods have also been used to study the temperature field of dams, but, the majority of these works aim to control the temperature stress in the mass concrete pouring process $[20,21]$. These methods could also be utilized to find the main influence factors and also investigate the temperature field of embankment dams affected by seepage, during the operation. To the authors' knowledge, no related research exists in this field and so this study was designed to do fill that gap. To meet this need, a commercial finite element numerical simulation software was implemented to simulate the hydrothermal coupling process of the embankment dam. The Morris global sensitivity analysis method was also employed to perform a sensitivity study and find the degrees of influence of the input parameters - including: the hydraulic conductivity $\left(K_{s}\right)$, saturated water content $\left(\theta_{s}\right)$, residual water content $\left(\theta_{r}\right)$, soil density $\left(\rho_{s}\right)$, specific heat capacity $\left(c_{s}\right)$ and porosity $(n)$ - on the embankment dam temperature. Furthermore, the temporal and spatial variations of the mean $(\mu)$ and deviation $(\sigma)$ of the fore-mentioned parameters are also analyzed, which provides clues to correct the model and improve the numerical simulation accuracy. Results of this study provide a scientific basis for further research work to make more accurate predictions for temperature field of embankment dams.

\section{Hydrothermal Coupling Model (HTCM)}

Richards's equation describes the saturated-unsaturated transient seepage field of embankment dams and is written as follows [22]:

$$
\begin{aligned}
& \rho_{w}\left(\frac{C_{m}}{\rho_{w} g}+S_{e} S_{s}\right) \frac{\partial p}{\partial t}+\nabla \rho\left(-\frac{K_{s} K_{r}(\theta)}{\mu(T)} \nabla\left(p+\rho_{w} g z\right)\right) \\
& \quad=Q_{m}
\end{aligned}
$$

where $\rho_{w}$ is the water density, $C_{m}$ is the specific water capacity, $g$ is the gravity acceleration, $S_{e}$ is the relative degree of saturation, $S_{s}$ is the elastic water storage rate, $p$ is the pressure, $\theta$ is the water content, $K_{s}$ is media saturated hydraulic conductivity, $K_{r}(\theta)$ is the unsaturated zone relative hydraulic conductivity, $\mu(T)$ is the dynamic viscosity of water, $z$ is the elevation of calculated point position, and $Q_{m}$ is the water source.

The dynamic viscosity of water is given as a function of temperature [23]:

$$
\mu(T)=0.00002414 \times 10^{(247.8 /(T+133.16))}
$$

The matrix suction and hydraulic conductivity in the unsaturated zone are functions of soil water content. The van Genuchten model is commonly used to describe the soil moisture characteristic curve [24]:

$$
\begin{aligned}
\theta & =\theta_{r}+S_{e}\left(\theta_{s}-\theta_{r}\right) \\
S_{e} & =\frac{1}{\left(1+\left|\alpha h_{p}\right|^{n_{v}}\right)^{m}} \\
C_{m} & =\frac{\alpha m}{1-m}\left(\theta_{s}-\theta_{r}\right) S_{e}^{1 / m}\left(1-S_{e}^{1 / m}\right)^{m} \\
K_{r}(\theta) & =S_{e}^{1 / 2}\left[1-\left(1-S_{e}^{1 / m}\right)^{m}\right]^{2}
\end{aligned}
$$

In the above relations, $\theta_{r}$ and $\theta_{s}$ are the residual and saturated water contents, respectively. Also, $\alpha$ is the reciprocal of the moisture characteristic curve intake. $h_{p}$ is the hydraulic pressure head $\left(h_{p}=p_{w} / \rho_{w} g\right)$, which in the unsaturated zone is equal to the negative pressure head, $h_{c} . n_{v}$ is an indicator of the slope of the moisture characteristic curve and is obtained by fitting the soil moisture characteristic curve, $m=1-1 / n_{v}$. 
The saturated-unsaturated heat transfer model can be expressed by the following equation [25]:

$$
\begin{aligned}
\frac{\left(\rho_{e q} c_{e q} T\right)}{t}= & \left(\lambda_{e q} \nabla T\right)+\left(\theta \rho_{w} c_{w} \mathbf{D}_{\mathbf{H}} \nabla T\right)-\left(\theta \rho_{w} c_{w} \mathbf{u} T\right) \\
& +Q_{s}
\end{aligned}
$$

where $\rho_{e q}$ is equivalent density, $c_{e q}$ is equivalent specific heat capacity, $\mathrm{T}$ is water temperature, $t$ is time, $\nabla$ is a Laplace operator, $\lambda_{e q}$ is equivalent thermal conductivity, $\theta$ is water content which is equal to porosity in the saturated zone, $\rho_{w}$ is water density, $c_{w}$ is the specific heat capacity of water, $\mathbf{u}$ is mean water velocity calculated by $\mathbf{u}=\mathbf{v} / \theta((\mathbf{v}$ is the Darcy seepage velocity), $Q_{s}$ is the heat source, $\mathbf{D}_{\mathbf{H}}$ is the hydrodynamic dispersion coefficient and is given by:

$$
\mathbf{D}_{\mathrm{Hij}}=\alpha_{T}|v| \delta_{i j}+\left(\alpha_{L}-\alpha_{T}\right) \mathbf{v}_{i} \mathbf{v}_{j}|v|
$$

where $\alpha_{T}$ and $\alpha_{L}$ are the transverse and longitudinal dispersion, $\mathbf{v}_{i}$ is the vector of flow velocity in direction $i$ and $\mathbf{v}_{j}$ is the vector of flow velocity in direction $j,|v|$ is the magnitude of flow velocity vector, $\delta_{i j}$ is a kriging constant, which is 1 when $i=j$ and 0 otherwise.

The equivalent density and specific heat capacity of the rock mass are estimated through volume-averaging, as follows:

$$
\begin{aligned}
& \rho_{e q}=(1-n) \rho_{s}+\theta \rho_{w}+(n-\theta) \rho_{g} \\
& c_{e q}=(1-n) c_{s}+\theta c_{w}+(n-\theta) c_{g}
\end{aligned}
$$

where the subscripts $s, w$ and $g$ represent the sand, water, and air, respectively.

The water content of any unsaturated porous media highly affect the equivalent thermal conductivity. At normal temperature conditions, the thermal conductivity of soil increases with the increase of water content. Several empirical models have been proposed to estimate the soil thermal conductivity and among them the Lu's model is more accurate and practical [26]. According to Lu's model, the thermal conductivity of unsaturated soil is a function of the thermal conductivity of dry soil $\left(\lambda_{d r y}\right)$ and that of the saturated soil $\left(\lambda_{\text {sat }}\right)$ and is given by:

$$
\lambda_{e q}(\theta)=\left(\lambda_{s a t}-\lambda_{d r y}\right) K_{e}+\lambda_{d r y}
$$

where $\lambda_{d r y}$ and $\lambda_{\text {sat }}$ are estimated by the following relations:

$$
\begin{aligned}
& \lambda_{d r y}=-0.56 n+0.51 \\
& \lambda_{s a t}=\lambda_{s}^{1-n} \lambda_{w}^{n}
\end{aligned}
$$

in which $\lambda_{s}$ is the thermal conductivity of soil obtained from the quartz content $(q)$, its thermal conductivity $\left(\lambda_{q}=\right.$ $\left.7.7 \mathrm{~W} /\left(\mathrm{m} \cdot{ }^{\circ} \mathrm{C}\right)\right)$, and the thermal conductivity of other minerals $\left(\lambda_{o}\right)$, ie., $\lambda_{s}=\lambda_{q}^{q} \lambda_{o}^{1-q}$. Among them, $\lambda_{o}=2.0 \mathrm{~W} /\left(\mathrm{m} \cdot{ }^{\circ} \mathrm{C}\right)$ $(q>0.2) ; \lambda_{o}=3.0 \mathrm{~W} /\left(\mathrm{m} \cdot{ }^{\circ} \mathrm{C}\right)(q \leq 0.2)$ and $\lambda_{w}$ is the thermal conductivity of water.
For conventional soil, the normalized thermal conductivity $K_{e}$, in (11), is expressed by the following:

$$
K_{e}=\exp \left\{\alpha\left[1-S_{r}^{(\alpha-1.33)}\right]\right\}
$$

where $S_{r}$ is the degree of saturation, $\alpha$ is the soil texturedependent parameter, and its values for sand, loam, and clay are $1.05,0.9$, and 0.58 , respectively. The value of 1.33 , in (14), indicates the shape parameter.

The surface temperature data observed by the meteorological department are usually discrete and finite. Hence, it is necessary to perform a finite Fourier series transformation on the observed data to obtain a Fourier series function that expresses the periodic behavior of the surface temperature with time:

$$
T(t)=T_{0}+\sum_{l=1}^{n}\left(A_{l} \cos \frac{2 \pi l t}{L}+B_{l} \sin \frac{2 \pi l t}{L}\right)
$$

where $T_{0}$ is the annual average temperature and $l$ is the order of the Fourier series, $l=1,2,3, \ldots, 5$. Also, $A_{l}$ and $B_{l}$ are the coefficients of the Fourier series. In this study, the period of $L$ is considered to be 365 days.

The above model can describe the hydrothermal state of the embankment dam. In the subsequent section, first, the convective heat transfer process in the embankment dam is considered to find the temperature field. Next, the influence of the unsaturated zone on the seepage and the temperature field is considered. Finally, the effect of cyclic fluctuations of atmosphere temperature on dam operation is considered. COMSOL Multiphysics software, a finite element numerical solver, is used to numerically resolve the governing equations, through modification of the relevant modules of the software. Accordingly, the saturated-unsaturated seepage and temperature fields can be obtained.

\section{The Morris Method}

Morris proposed his sensitivity analysis method in 1991 [15]. This method is also called the elementary effects method [27], which can effectively identify and rank the importance of input parameters of a model by changing the value of only one parameter in an instance and finding its effect on the model output. Therefore, it is possible to calculate the "elementary effect (EE)" of each parameter on the output, one by one, and finally evaluate the influence of all of them on the results. On this basis, sensitivity factors can be compared globally and the nonlinearity of the model can be described qualitatively.

The experimental plan is composed of individually random One-At-a-Time (OAT) experiments. Each model input $X_{i}(i=1, \ldots, k)$ is assumed to vary across $p$ selected levels in the space of the input factors. Hence, the region of experimentation, $\boldsymbol{\Omega}$, is a $k$-dimensional $p$-level grid. According to the principle of Morris sensitivity analysis, the factors are assumed to be uniformly distributed in the range of $[0,1]$ and are then transformed from the unit hypercube to their actual distribution space. 
TABLE 1: Seepage and temperature fields parameters used in the numerical model.

\begin{tabular}{|c|c|c|c|c|c|c|c|c|c|c|}
\hline \multirow{2}{*}{ Dam material } & \multirow{2}{*}{$K_{s}(\mathrm{~cm} / \mathrm{s})$} & \multicolumn{2}{|c|}{ Water content } & \multicolumn{2}{|c|}{ VG parameters } & \multirow{2}{*}{$S_{s}\left(\mathrm{~Pa}^{-1}\right)$} & \multirow{2}{*}{$n(\%)$} & \multicolumn{2}{|c|}{ Solid medium } & \multirow{2}{*}{$q(\%)$} \\
\hline & & $\theta_{s}\left(\mathrm{~cm}^{3} / \mathrm{cm}^{3}\right)$ & $\theta_{r}\left(\mathrm{~cm}^{3} / \mathrm{cm}^{3}\right)$ & $\alpha\left(\mathrm{m}^{-1}\right)$ & $\beta$ & & & $c_{s} \mathrm{~J} /\left(\mathrm{kg} \cdot{ }^{\circ} \mathrm{C}\right)$ & $\rho_{s}\left(\mathrm{~kg} / \mathrm{m}^{3}\right)$ & \\
\hline Dam fill material & $4.53 \times 10^{-5}$ & 0.441 & 0.191 & 1.90 & 1.31 & $10^{-6}$ & 38 & 800 & 1740 & 35 \\
\hline Drainage prism material & $1.00 \times 10^{-2}$ & 0.420 & 0.027 & 23.2 & 2.75 & $10^{-7}$ & 50 & 800 & 2600 & 62 \\
\hline Dam foundation material & $3.33 \times 10^{-3}$ & 0.380 & 0.013 & 1.51 & 0.38 & $10^{-6}$ & 48 & 800 & 1620 & 30 \\
\hline Anti-seepage wall material & $8.64 \times 10^{-6}$ & 0.490 & 0.123 & 0.80 & 1.09 & $10^{-8}$ & 10 & 967 & 2694 & 25 \\
\hline
\end{tabular}

For a given value of $\mathbf{X}$, the elementary effect of the $i$ th input factor on the model is defined as follows [28]:

$$
\begin{aligned}
& E E_{i}(\mathbf{X}) \\
& =\frac{f\left(X_{1}, \ldots, X_{i-1}, X_{i}+\Delta, X_{i+1}, \ldots, X_{k}\right)-f(\mathbf{X})}{\Delta}
\end{aligned}
$$

where $\Delta$ is a perturbation value that is selected from the collection $\{1 /(p-1), \ldots, 1-1 /(p-1)\}, p$ is the number of levels, $\mathbf{X}=\left(X_{1}, X_{2}, \ldots, X_{k}\right)$ is any selected value in $\mathbf{\Omega}$, such that the transformed point $\left(\mathbf{X}+\mathbf{e}_{i} \Delta\right)$ is still in $\Omega$ for each index $i=1, \ldots, k$, and $\mathbf{e}_{i}$ is a vector of zeros, but with a unit as its $i$ th component. The finite distribution of each elementary effect of the $i$ th input factor on the output is obtained by randomly sampling different $\mathbf{X}$ vectors from $\boldsymbol{\Omega}$ and is denoted by $F_{i}$, (i.e., $\left.E E_{i}(\mathbf{X}) \sim F_{i}\right)$. The number of elements of each $F_{i}$ is $p^{k-1}[p-\Delta(p-1)]$ (for more details, see $\left.[15,28,29]\right)$.

In addition, Morris proposed two sensitivity measures for each elementary factor, $\mu$ and $\sigma$, which are, respectively, the mean and standard deviation of $F_{i}$. In order to estimate these quantities, Morris suggested performing sampling on $r$ elementary effects from each $F_{i}$ via an efficient design that constructs $r$ trajectories of $(k+1)$ points in the input space, each providing $k$ elementary effects, one per input factor. The total cost of the experiment is thus $r(k+1)$ [28]. The formula for computing $\mu$ and $\sigma$ is given by the following [29]:

$$
\begin{aligned}
\mu_{i} & =\frac{1}{N} \sum_{r}^{N} E E_{i, r} \\
\sigma_{i} & =\sqrt{\frac{1}{N-1} \sum_{r=1}^{n}\left(E E_{i, r}-\mu_{i}\right)^{2}}
\end{aligned}
$$

where $E E_{i, r}$ corresponds to the $r$ th $E E$ of $X_{i}$ and $N$ is the sample size. The higher the value of $\mu$, the greater the influence of the corresponding parameters on the output value of the model. The higher the value of $\sigma$, the greater the interaction of a certain parameter with other parameters. Thus, the effect of that certain parameter has on the model output is nonlinear.

\section{Case Study}

4.1. Description of the Site. The reservoir chosen for this study is located in the middle reaches of the Heiheze River, a primary tributary of the Wuding River (the primary tributary of the Yellow River) in Shaanxi Province, China. The length of the channel above the dam site is $14.3 \mathrm{~km}$, the control basin area is $117.4 \mathrm{~km}^{2}$, and its gradient is $5.03 \%$. The normal water storage level of the reservoir is $1207.00 \mathrm{~m}$, the designed flood level is $1208.50 \mathrm{~m}$, and the check flood level is $1209.03 \mathrm{~m}$. The total capacity of this reservoir, as a daily regulating one, is 4.86 million $\mathrm{m}^{3}$. This project is designed for a residential water supply, irrigation water supply, and drought relief and its construction has a great significance for local economic development. The hub building consists of three parts: (1) the water retaining dam; (2) the water discharge culvert; and (3) the diversion culvert. The water discharge culvert is arranged parallel to the diversion culvert, which is located on the right bank of the dam, and the water discharge and diversion towers are combined together. The layout of the hub building is shown in Figure 1.

4.2. Model Setup. The coupled characteristics of saturatedunsaturated transient seepage and temperature fields of the embankment dam was solved using the numerical solver, and the results are presented in the following sections.

4.2.1. Geometric Model. Figure 2 depicts a schematic of the dam structure. The embankment dam is homogeneously filled with silty clay with a crest length of $282.1 \mathrm{~m}$, crest width of $5 \mathrm{~m}$, crest elevation of $1210 \mathrm{~m}$, and a maximum height of $16.2 \mathrm{~m}$. The slope ratio upstream of the dam is $1: 3$ with the concrete slope protection. The slope ratio downstream of the dam is $1: 2.5$, and a $1.5 \mathrm{~m}$ width berm is set at the elevation of $1203 \mathrm{~m}$. The drainage prism is made of gravel and is designed in the dam toe. The homogeneous soil is used as an impervious material for the dam body and the concrete antiseepage wall is utilized as the thick overburden layer to prevent seepage. The thickness of the antiseepage wall is 0.8 $\mathrm{m}$ and the upper part of the wall body inside the dam body is $2 \mathrm{~m}$. The abutment antiseepage wall enters $60 \mathrm{~m}$ into the abutment.

4.2.2. Model Parameters. Referring to the customary engineering design data and literature, the influencing parameters to account for the seepage and temperature fields are given in Table 1. Among these parameters, the unsaturated seepage parameters are selected from $[1,4,30]$, and the other parameters are based on empirical evaluations and engineering design data [31]. The thermal diffusion coefficient is $0.01 \mathrm{~m}$, and the thermal conductivity of air and water are, respectively, considered to be $0.024 \mathrm{~W} /\left(\mathrm{m} \cdot{ }^{\circ} \mathrm{C}\right)$ and $0.58 \mathrm{~W} /\left(\mathrm{m} \cdot{ }^{\circ} \mathrm{C}\right)$. The heat capacity of air and water are $1005 \mathrm{~J} /\left(\mathrm{kg} \cdot{ }^{\circ} \mathrm{C}\right)$ and 4186 $\mathrm{J} /\left(\mathrm{kg} \cdot{ }^{\circ} \mathrm{C}\right)$, respectively, and the density of air and water are $1.205 \mathrm{~kg} / \mathrm{m}^{3}$ and $1000 \mathrm{~kg} / \mathrm{m}^{3}$, respectively. 

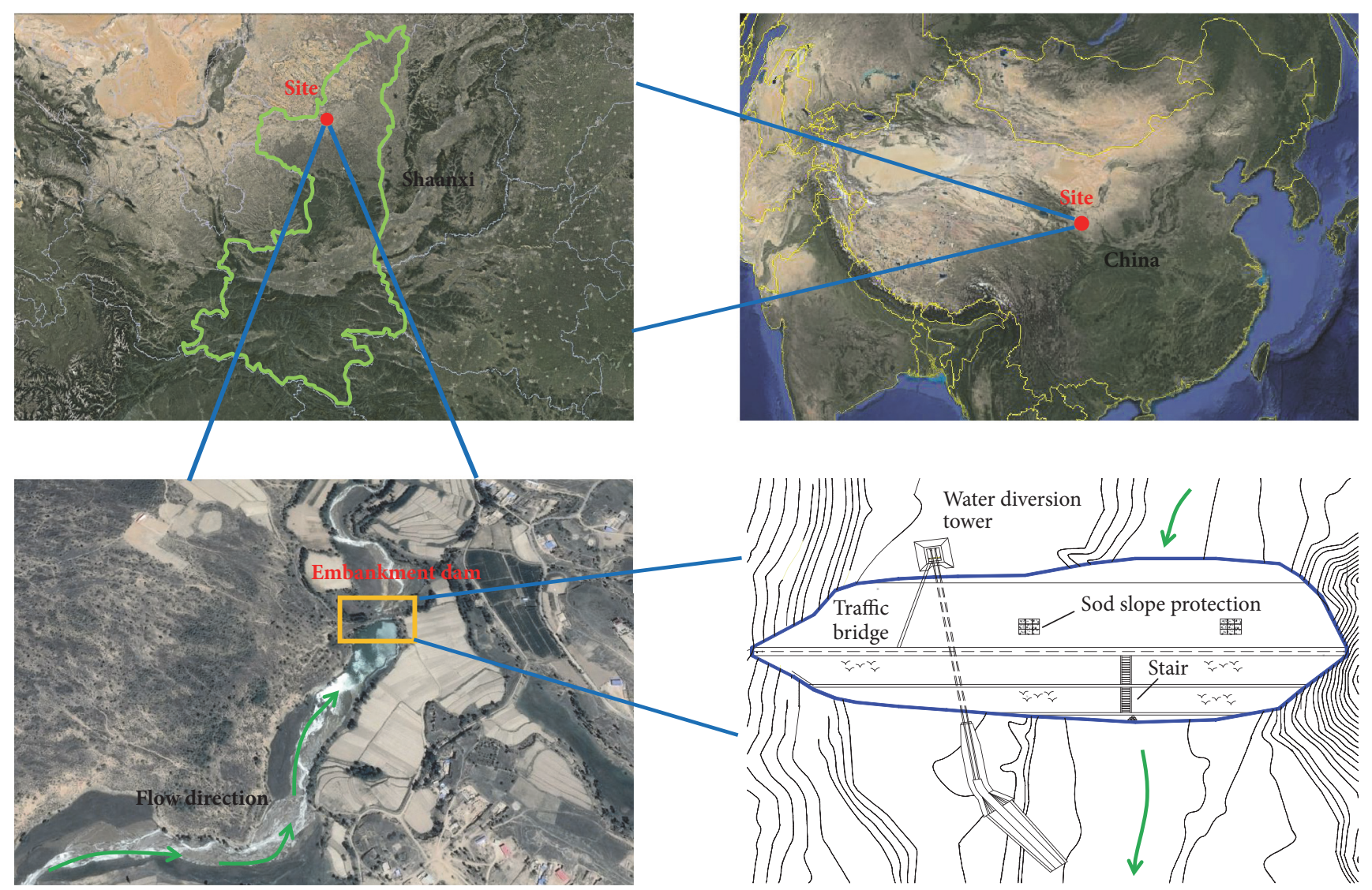

FIGURE 1: The geographical location and layout of the embankment dam.

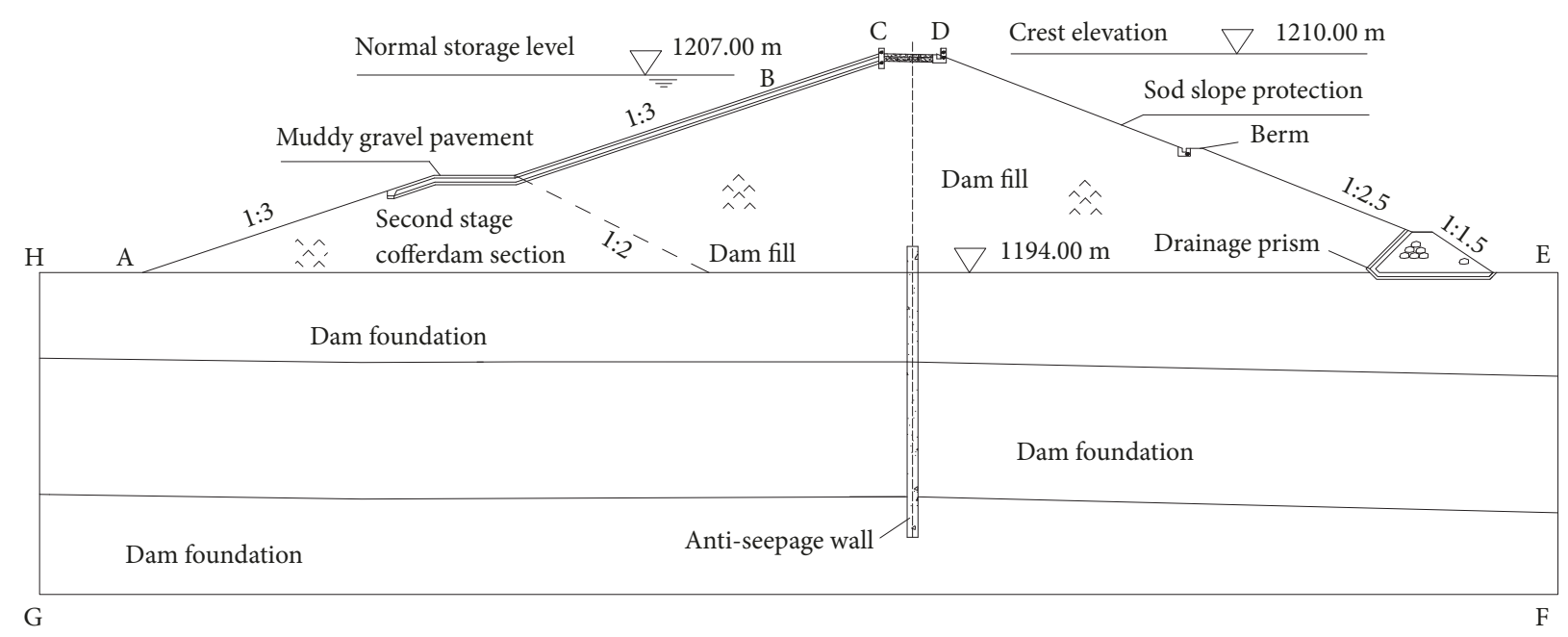

FIGURE 2: Diagram of embankment dam structure (A through $\mathrm{H}$ are the boundary numbers).

4.2.3. Initial and Boundary Conditions. For the saturatedunsaturated seepage field, the upstream dam body, H-A$\mathrm{B}-\mathrm{C}$ in Figure 2 and downstream, D-E in Figure 2, dam bodies are considered as constant water head boundaries. The water head on the upstream body is $13.2 \mathrm{~m}$ and the dam surface head changes linearly according to its buried depth. A water head of $0 \mathrm{~m}$ is considered for the downstream boundary. The other boundaries are considered as zero flux boundaries.

For the temperature field, the H-A-B boundary, below the reservoir water surface, is selected according to the annual variations of the reservoir water temperature, as follows: 


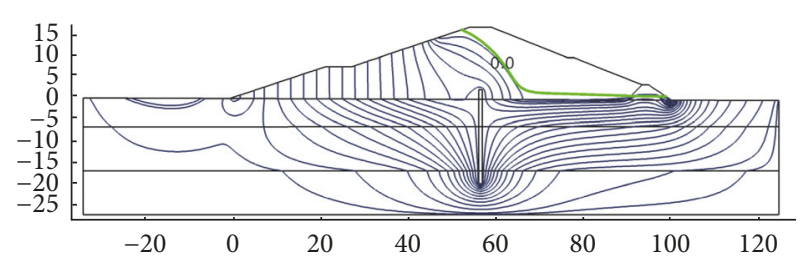

(a)

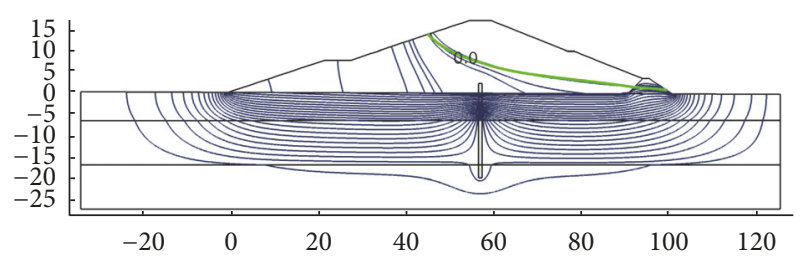

(c)

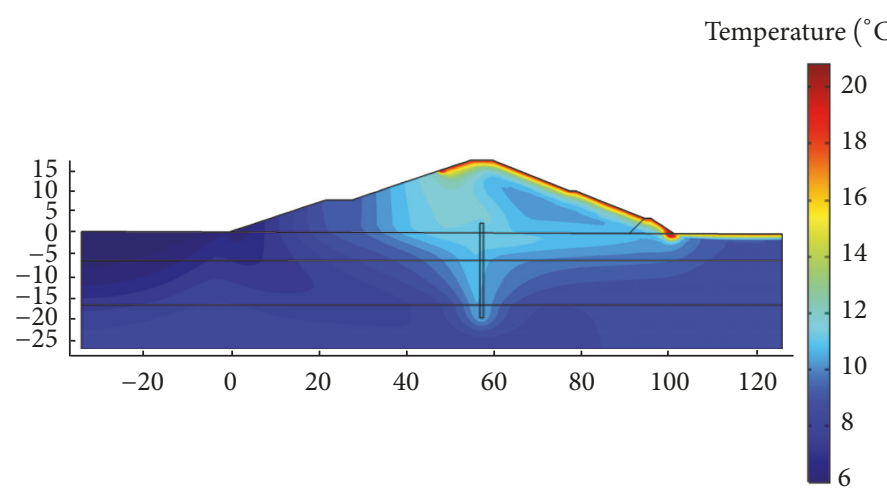

(b)

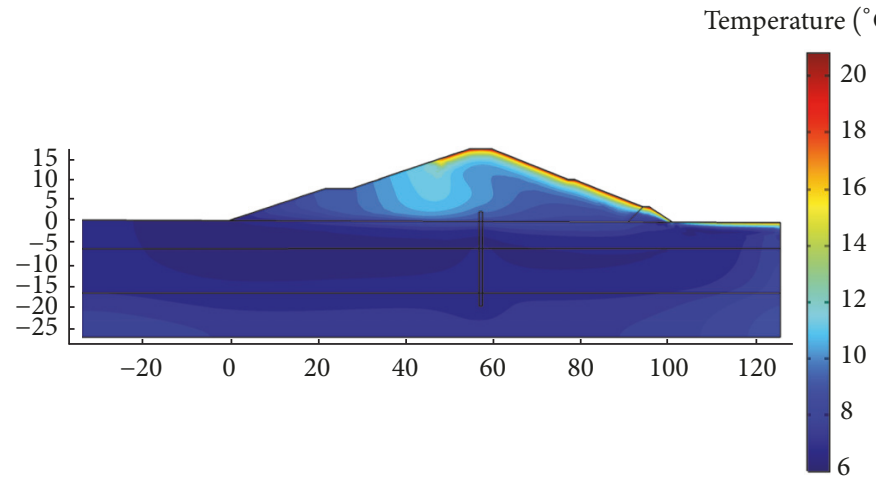

(d)

FIGURE 3: Comparison of the seepage and temperature fields of the dam, with and without a concentrated leakage at the same time (June 22, 2020): (a) the dam seepage field without leakage; (b) the dam temperature field without leakage; (c) the dam seepage field in presence of the leakage; $(\mathrm{d})$ the dam temperature field in presence of the leakage.

$$
\begin{aligned}
T(y, t)=11.37 \mathrm{e}^{-0.005(13.2-y)}+12.34 \mathrm{e}^{-0.012(13.2-y)} \\
\cdot \cos \frac{\pi}{6} \\
\cdot[t-6.5-(0.53+0.008(13.2-y))]
\end{aligned}
$$

where $y$ is the reservoir water level elevation in meters, and $t$ is the time.

The bottom boundary, E-F-G-H in Figure 2, is adiabatic. The B-C-D-E boundary, above the reservoir water surface, is in contact with the atmosphere which follows from seasonal temperature fluctuations and measured by daily average temperature. The local scattered temperature data from China Meteorological Information Center (http://data.cma.cn) are used in this study. In addition, the temperature fluctuation model of the year is obtained by using the Fourier series (see (15)) and is used as a periodic temperature boundary. The 5th-order Fourier series can meet the required accuracy. The Fourier series coefficients of the annual temperature regression model are as follows: $T_{0}=8.8141, A_{1}=-14.241$, $A_{2}=-1.0891, A_{3}=-0.3545, A_{4}=-0.0169, A_{5}=0.0563, B_{1}$ $=-2.5332, B_{2}=-0.3466, B_{3}=-0.2486, B_{4}=0.1595, B_{5}$ $=-0.0471$. This Fourier series can be used to determine the temperature fluctuations at any time, and its calculated average annual temperature is $8.8^{\circ} \mathrm{C}$.
The pressure head of $0 \mathrm{~m}$ and the annual average temperature of $8.8^{\circ} \mathrm{C}$ are considered to be the initial conditions of the seepage and temperature fields.

4.3. Embankment Dam Seepage: Temperature Fields Analysis. An abnormal leakage from the embankment dam will change the dam body temperature. Using the thermal monitoring technology in embankment dams, existence of any abnormal temperature variation can be detected in the field, at any time. The temperature tracing detection technology also helps to determine concentrated leakages in embankment dams. Accordingly, these two methods make it possible to find leakage through the temperature field. Hence, a leakage problem in the dam is identified and is simulated to investigate the influences of concentrated leakage on the temperature field of the dam. It is assumed that the antiseepage wall has a fine $(0.02 \mathrm{~m})$ width crack at a specific time. The leakage is positioned at depth of $6.2 \mathrm{~m}$ from the bottom of the dam. The simulation time is 2880 days, and the simulation time of concentrated leakage is 731 days, using 1-day time steps. In this manner, the sharp temperature variations of the dam body under the concentrated seepage condition are obtained.

The seepage and temperature contours of the dam, with and without a concentrated leakage, at the same time are shown in Figure 3. When no concentrated leakage exists (see Figures 3(a) and 3(b)), the phreatic line is in a relatively low 
TABLE 2: Probability distribution of hydro-thermal parameters of the embankment dam.

\begin{tabular}{lccc}
\hline Parameters & Symbol & Units & Parameter-observed probability distribution \\
\hline Hydraulic conductivity & $K_{s}$ & $\mathrm{~cm} / \mathrm{s}$ & $K_{s} \sim\left(10^{-7}, 10^{-5}\right)$ \\
Saturated water content & $\theta_{s}$ & $\mathrm{~cm}^{3} / \mathrm{cm}^{3}$ & $\theta_{s} \sim(0.36,0.49)$ \\
Residual water content & $\theta_{r}$ & $\mathrm{~cm}^{3} / \mathrm{cm}^{3}$ & $\theta_{r} \sim(0.013,0.190)$ \\
Soil density & $\rho_{s}$ & $\mathrm{~kg} / \mathrm{m}^{3}$ & $\rho_{s} \sim(1390,2690)$ \\
Specific heat capacity of solids & $c_{s}$ & $\mathrm{~J} /\left(\mathrm{kg} \cdot{ }^{\circ} \mathrm{C}\right)$ & $c_{s} \sim(400,1500)$ \\
Porosity & $n$ & $\%$ & $n \sim(21,68)$ \\
Thermal conductivity & $\lambda$ & $\mathrm{W} /\left(\mathrm{m} \cdot{ }^{\circ} \mathrm{C}\right)$ & $\lambda \sim(0.25,5.03)$ \\
\hline
\end{tabular}

position. The temperature gradually increases from the lowtemperature zone of the reservoir water, in front of the antiseepage wall, to the high-temperature zone on the surface of the dam body. In this condition, the isotherms are distributed in a relatively uniform pattern. When the leakage occurs (Figures 3(c) and 3(d)), obviously the phreatic line rises and the reservoir water in front of the antiseepage wall seeps into the unsaturated zone through the concentrated leakage zone. A sudden temperature change region with dense isotherms is formed in front of the antiseepage wall and the dam body temperature, behind the antiseepage wall, is lowered as a consequence of passing the low-temperature reservoir water through the concentrated leakage zone. Hence, the influence of the air temperature becomes smaller.

Therefore, presence of the concentrated leakage caused the low-temperature reservoir water to flow, mainly through the concentrated leakage zone, into the downstream and changed the spatial distribution of the surrounding temperature field as a result of the convective heat transfer within the path of the low-temperature reservoir water. Temperature measurement data of the embankment dam depicts that the temperature field (in time and space) can be affected by the presence of concentrated leakages, and the seepage field can be predicted by an inverse procedure through temperature measurement.

The seepage velocity and temperature variations over time at the outlet of the concentrated seepage zone of the antiseepage wall as exhibited in Figure 4 show that the concentrated seepage begins at the $731^{\text {st }}$ day of the simulation time and leads to an incremental jump in the seepage velocity from $3.9 \times 10^{-8} \mathrm{~m} / \mathrm{s}$ (before leakage) to $7.6 \times 10^{-6} \mathrm{~m} / \mathrm{s}$, after which the seepage velocity gradually becomes stable. Before leakage initiation, the temperature at the outlet of the antiseepage wall was approximately $10.5^{\circ} \mathrm{C}$ with little variation. However, when leakage starts, the outlet temperature rapidly declines to $9.8^{\circ} \mathrm{C}$ and then decreases at a slower rate to the lowest temperature of $8.5^{\circ} \mathrm{C}$, over a period of 100 days. In this condition, the outlet temperature is consistent with the trend of variations of the water temperature at the bottom of the reservoir. After the leakage of the antiseepage wall, the seepage outlet leakage velocity increases rapidly, and the lowtemperature water flows through the bottom of the leakage passage; hence, the leakage outlet temperature will change. Accordingly, the outlet temperature variation is in line with the reservoir water temperature. It can be concluded that the temperature variations during the time is sensitive to the leakage and can effectively indicate the location and time

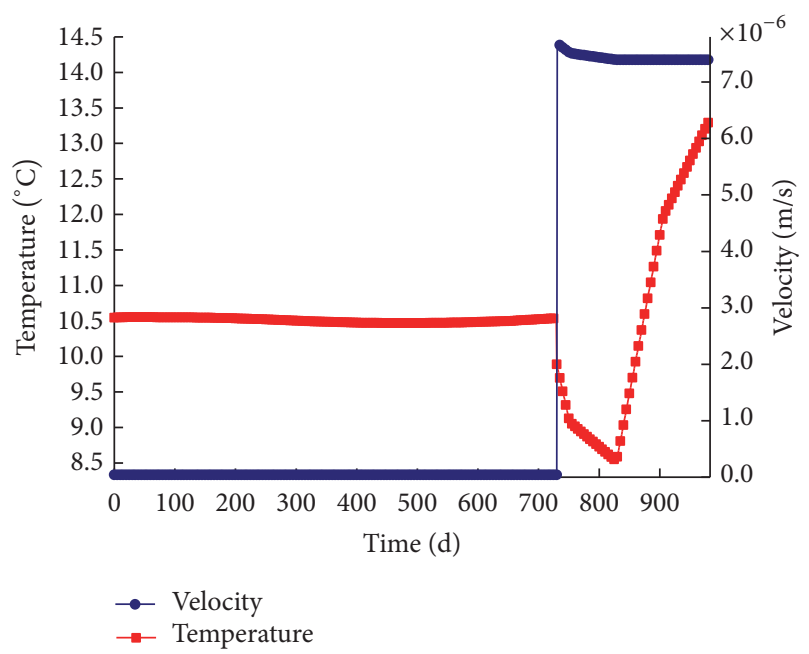

FIGURE 4: Flow velocity and temperature variations along the time at the crack of the antiseepage wall.

of the leakage. Thus it is feasible to detect the leakage of embankment dams through temperature measurements.

4.4. Morris Global Sensitivity Analysis. Since a coupled hydrothermal problem is considered, the dam temperature field should be affected by both the regional thermal condition and the seepage characteristics. Assuming that the computational domain is quite large, it can also be assumed that no heat exchange between the seepage system in the dam body and the geological body occurs. Therefore, the main influencing thermal boundaries are the following two known temperature boundaries: (1) the water temperature at the bottom of the upstream reservoir; and (2) the temperature at the surface of the downstream dam. The principal parameters of the seepage medium that can affect the temperature field are the hydraulic conductivity, the saturated water content, the residual water content, the specific heat capacity, the porosity, and the thermal conductivity. In order to reduce the computational costs, only a transverse section of the dam is selected to be analyzed.

The ranges of variation of hydraulic and thermal properties of the soil are summarized in Table 2, according to the literature $[24,30,32]$. In addition, the range of porosity variations is selected from typical values of different types of soil [33]. 


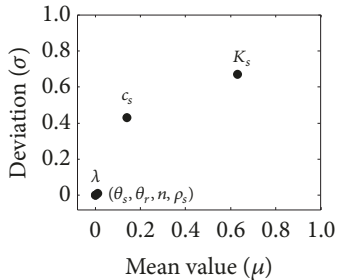

(a) $1^{\#}$

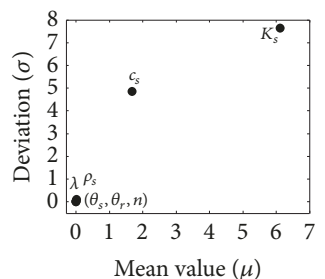

(f) $6^{\#}$

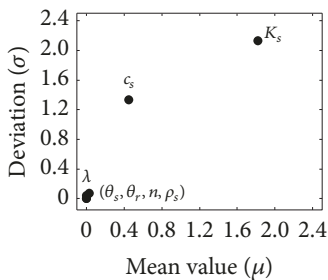

(b) $2^{\#}$

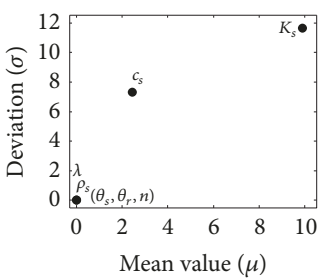

(g) $7^{\#}$

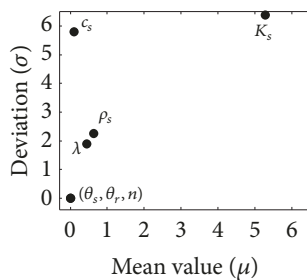

(c) $3^{\#}$

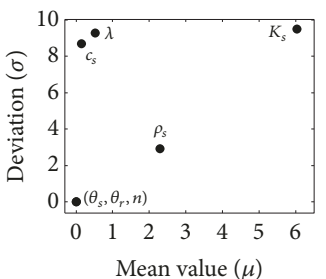

(h) $8^{\#}$

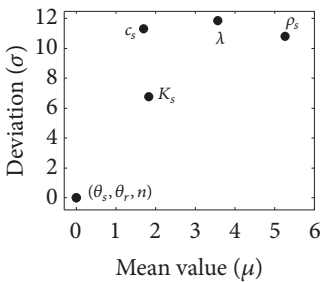

(d) $4^{\#}$

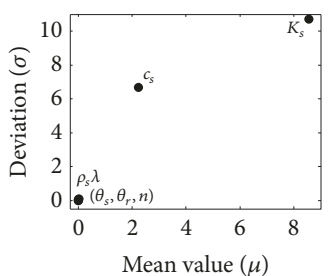

(i) $9^{\#}$

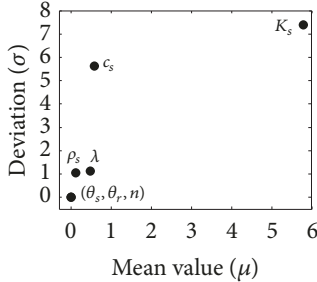

(e) $5^{\#}$

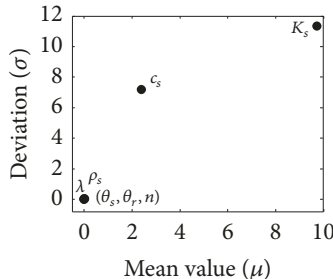

(j) $10^{\#}$

FIGURE 5: Morris test results for the 10 monitoring points.

TABLE 3: A sampling example of hydro-thermal parameters of the embankment dam.

\begin{tabular}{lc}
\hline Sample & Trajectory 1 \\
\hline 1 & $\left(7.17 \times 10^{-6}, 0.434,0.038,2504,400,34.4,2.299\right)$ \\
2 & $\left(7.17 \times 10^{-6}, 0.434,0.038,2504,400,27.7,2.299\right)$ \\
3 & $\left(7.17 \times 10^{-6}, 0.434,0.038,2690,400,27.7,2.299\right)$ \\
4 & $\left(5.76 \times 10^{-6}, 0.434,0.038,2690,400,27.7,2.299\right)$ \\
5 & $\left(5.76 \times 10^{-6}, 0.434,0.038,2690,400,27.7,2.981\right)$ \\
6 & $\left(5.76 \times 10^{-6}, 0.434,0.038,2690,557,27.7,2.981\right)$ \\
7 & $\left(5.76 \times 10^{-6}, 0.434,0.013,2690,557,27.7,2.981\right)$ \\
8 & $\left(5.76 \times 10^{-6}, 0.416,0.013,2690,557,27.7,2.981\right)$ \\
\hline
\end{tabular}

Following the experimental procedure of the Morris method, 80 sample groups of the selected hydrothermal parameters $\left(K_{s}, \theta_{s}, \theta_{r}, \rho_{s}, c_{s}, n, \lambda\right)$ were obtained using 10 trajectories and 8 levels sampling, where $X_{i, j}(i=1, \ldots, 10 ; j=$ $1, \ldots, 8)$ is the sensitivity factor of the $i$ th trajectory and the $j$ th vector. As an example, the sampling results of the first trajectory are listed in Table 3.

The 80 groups of sample parameter vectors obtained by sampling were substituted into COMSOL Multiphysics software to start the simulation. Next, the temperature variations of the embankment dam at the monitoring points were obtained. Four monitoring points were set along the horizontal direction with the coordinates of $1^{\#}(20,5), 2^{\#}$ $(40,5), 3^{\#}(60,5)$, and $4^{\#}(80,5)$. In the vertical direction, three monitoring points are set, either before or after the antiseepage wall, with the following coordinates: $5^{\#}(55,10)$, $6^{\#}(55,-5), 7^{\#}(55,-20), 8^{\#}(60,10), 9^{\#}(60,-5)$, and $10^{\#}$ $(60,-20)$. As an example, using trajectory 1 , the temperature values at the eight monitoring points, calculated by the numerical solver, are listed in Table 4.

After the numerical simulation of 80 groups of the sample parameters, the temperature values at the 10 monitoring points can be obtained. Next, the sensitivity index, $\mu$, and deviation, $\sigma$, of the seven parameters were calculated according to the test procedure of the Morris method. Table 5 shows $\mu$ and $\sigma$ of each parameter affected by the temperature in the ten monitoring points at the $2880^{\text {th }}$ time step. In order to compare the influence of each parameter on the temperature values of the model, the absolute deviation values of Table 5 are also exhibited as scatter plots in Figure 5.

The $\mu$ and $\sigma$ values of the ten mentioned monitoring points are different, and there are certain fluctuations in their trend of variations. Moving horizontally from the dam body upstream to its downstream (point 1 to point 4), and also moving vertically from the dam crest to the dam foundation (point 5 to point 7 and point 8 to point 10), the influences of parameters on temperature values are increasing, both before and after the antiseepage wall. Also in these two directions, as shown in Table 5, the conjugate interaction of parameters is also increasing, when they affect the model temperature output.

It can be seen from Figure 5 that though the $\mu$ value of the 10 monitoring points is varying with the position, but the mean value $(\mu)$ of the hydraulic conductivity $\left(K_{s}\right)$ and the specific heat capacity $\left(c_{s}\right)$ is generally larger than the other parameters. Hence, these two parameters are affecting the model output, the temperature, in a significant way. On the other hand, the corresponding mean values $(\mu)$ of the thermal conductivity $(\lambda)$, the saturated water content $\left(\theta_{s}\right)$, the residual water content $\left(\theta_{r}\right)$, the porosity $(n)$, and the soil density $\left(\rho_{s}\right)$ are relatively small. As a consequence, these parameters have a little impact on the model output. Furthermore, among all of the input parameters, the hydraulic conductivity $\left(K_{s}\right)$ has the highest impact on the temperature field. Also, the zero sensitivity indices of the saturated water content $\left(\theta_{s}\right)$, the residual water content $\left(\theta_{r}\right)$, and the porosity $(n)$ reveal that they have the minimum impact on the model output. Therefore, their influence on temperature variations of the dam can be neglected. 
TABLE 4: Temperature at the 10 monitoring points of the embankment dam.

\begin{tabular}{lcccccccccc}
\hline \multirow{2}{*}{ Sample } & & \multicolumn{9}{c}{ Temperature value of each monitoring point $\left({ }^{\circ} \mathrm{C}\right)$} \\
$1^{\#}$ & $2^{\#}$ & $3^{\#}$ & $4^{\#}$ & $5^{\#}$ & $6^{\#}$ & $7^{\#}$ & $8^{\#}$ & $9^{\#}$ & $10^{\#}$ \\
\hline 1 & 8.9917 & 10.9409 & 11.7681 & 11.3842 & 11.8443 & 11.1437 & 10.9288 & 12.8233 & 11.3093 & 10.9299 \\
2 & 8.9917 & 10.9409 & 11.7681 & 11.3842 & 11.8443 & 11.1437 & 10.9288 & 12.8233 & 11.3093 & 10.9299 \\
3 & 8.9917 & 10.9408 & 11.7885 & 9.9169 & 11.9182 & 11.1438 & 10.9288 & 11.9406 & 11.3080 & 10.9299 \\
4 & 8.9807 & 10.9310 & 11.7581 & 9.0427 & 11.8846 & 11.1613 & 10.9188 & 14.0056 & 11.3378 & 10.9186 \\
5 & 8.9799 & 10.9304 & 11.7878 & 12.3193 & 11.9533 & 11.1603 & 10.9179 & 13.0001 & 11.3412 & 10.9177 \\
6 & 8.9799 & 10.9304 & 11.7811 & 10.6677 & 11.9678 & 11.1603 & 10.9179 & 13.0147 & 11.3415 & 10.9177 \\
7 & 8.9799 & 10.9304 & 11.7811 & 10.6677 & 11.9678 & 11.1603 & 10.9179 & 13.0147 & 11.3415 & 10.9177 \\
8 & 8.9799 & 10.9304 & 11.7811 & 10.6677 & 11.9678 & 11.1603 & 10.9179 & 13.0147 & 11.3415 & 10.9177 \\
\hline
\end{tabular}

TABLE 5: Morris test results of monitoring points of hydro-thermal parameters of the embankment dam.

\begin{tabular}{|c|c|c|c|c|c|c|c|c|c|c|c|}
\hline \multirow{2}{*}{ Morris index } & \multirow{2}{*}{ Parameters } & \multicolumn{10}{|c|}{ Monitoring results } \\
\hline & & $1^{\#}$ & $2^{\#}$ & $3^{\#}$ & $4^{\#}$ & $5^{\#}$ & $6^{\#}$ & $7^{\#}$ & $8^{\#}$ & $9^{\#}$ & $10^{\#}$ \\
\hline \multirow{7}{*}{$\mu$} & $K_{s}$ & 0.63 & 1.82 & 5.29 & 1.82 & 5.79 & 6.12 & 9.89 & 6.03 & 8.57 & 9.73 \\
\hline & $\theta_{s}$ & 0.00 & 0.00 & 0.00 & 0.00 & 0.00 & 0.00 & 0.00 & 0.00 & 0.00 & 0.00 \\
\hline & $\theta_{r}$ & 0.00 & 0.00 & 0.00 & 0.00 & 0.00 & 0.00 & 0.00 & 0.00 & 0.00 & 0.00 \\
\hline & $\rho_{s}$ & 0.00 & 0.00 & 0.64 & -5.26 & 0.12 & -0.01 & 0.00 & -2.29 & -0.01 & 0.02 \\
\hline & $c_{s}$ & 0.14 & 0.45 & 0.10 & 1.70 & 0.58 & 1.68 & 2.45 & -0.15 & 2.24 & 2.39 \\
\hline & $n$ & 0.00 & 0.00 & 0.00 & 0.00 & 0.00 & 0.00 & 0.00 & 0.00 & 0.00 & 0.00 \\
\hline & $\lambda$ & -0.01 & -0.03 & 0.44 & 3.57 & 0.47 & 0.00 & 0.00 & 0.53 & 0.03 & 0.00 \\
\hline \multirow{7}{*}{$\sigma$} & $K_{s}$ & 0.67 & 2.13 & 6.38 & 6.76 & 7.39 & 7.65 & 11.63 & 9.50 & 10.71 & 11.36 \\
\hline & $\theta_{s}$ & 0.00 & 0.00 & 0.00 & 0.00 & 0.00 & 0.00 & 0.00 & 0.00 & 0.00 & 0.00 \\
\hline & $\theta_{r}$ & 0.00 & 0.00 & 0.00 & 0.00 & 0.00 & 0.00 & 0.00 & 0.00 & 0.00 & 0.00 \\
\hline & $\rho_{s}$ & 0.00 & 0.04 & 2.25 & 10.79 & 1.05 & 0.10 & 0.01 & 2.92 & 0.07 & 0.06 \\
\hline & $c_{s}$ & 0.43 & 1.33 & 5.81 & 11.31 & 5.62 & 4.85 & 7.31 & 8.68 & 6.67 & 7.19 \\
\hline & $n$ & 0.00 & 0.00 & 0.00 & 0.00 & 0.00 & 0.00 & 0.00 & 0.00 & 0.00 & 0.00 \\
\hline & $\lambda$ & 0.01 & 0.07 & 1.88 & 11.86 & 1.12 & 0.04 & 0.03 & 9.27 & 0.09 & 0.03 \\
\hline
\end{tabular}

As was observed, the corresponding $\sigma$ values of $K_{s}$ and $c_{s}$ are large, indicating that these two parameters have the greatest interaction with the other parameters, when all parameters are affecting the temperature. In other words, temperature shows a nonlinear behavior with respect to these to parameters. Conversely, the deviation values $(\sigma)$ of $\lambda, \theta_{s}, \theta_{r}$, $n$, and $\rho_{s}$ are relatively small, indicating that the interaction between these five parameters and other parameters is small with respect to the temperature.

As was observed, when the $\mu$ value of one parameter is large, its corresponding $\sigma$ value will be large too. This fact indicates that the greater the influence of a parameter on the model output, the greater the interaction between that parameter and the other parameters. Therefore, in practical research, improving the observation accuracy of the hydraulic conductivity and the specific heat capacity can lead to more accurate simulation results, even without considering some other secondary factors.

In addition, results of Table 5 indicate that each parameter has both favorable and unfavorable effects on the model temperature value. These impacts can provide a certain reference for model correction. The favorable effects indicate that variations of the parameters are consistent with temperature variations, during the model calibration. The unfavorable effects indicate that fluctuations of the parameters are adversely changing the temperature value. In terms of this study, if a simulated temperature value of the dam is less than its measured value, the whole model can be adjusted by increasing the value of the favorable acting parameter or decreasing the value of the unfavorable acting one. Thus, the model can be corrected to obtain simulation results that are closer to the actual situation.

\section{Conclusions}

The main factors of the hydrothermal coupling model (HTCM) parameters affecting the temperature field of an embankment dam were investigated to reduce the workload in the model calibration process. The HTCM of an embankment dam, based on the thermal conductivity model of $\mathrm{Lu}$ et al. [26], was investigated using the commercial COMSOL Multiphysics finite element software. Comparison of the seepage and temperature fields of the dam, with and without concentrated hydrothermal coupling analysis, makes 
it possible to reasonably analyze probable anomalies in an embankment dam. The sensitivity of the influencing factors on the embankment dam's temperature field was analyzed implementing the Morris sensitivity method and results were presented in terms of the mean and deviation values. After investigation of the results, the following points can be concluded:

(1) Moving horizontally from upstream of the dam body to its downstream and also in the vertical direction from the dam crest to the dam foundation, both before and after the antiseepage wall, the temperature dependency on the input parameters is increasing. In addition, the interaction between each parameter and other ones is also increasing, when they affect the model output temperature.

(2) In general, the hydraulic conductivity $\left(K_{s}\right)$ and the soil specific heat capacity $\left(c_{s}\right)$ are dominantly affecting the model output (i.e., temperature), whereas the other parameters, including thermal conductivity $(\lambda)$, saturated water content $\left(\theta_{s}\right)$, residual water content $\left(\theta_{r}\right)$, the porosity $(n)$, and the soil density $\left(\rho_{s}\right)$, have less effect on the temperature. Furthermore, when affecting the temperature, the hydraulic conductivity $\left(K_{s}\right)$ and the soil specific heat capacity $\left(c_{s}\right)$ have a large interaction with other parameters, while the interactions between the other parameters are smaller. Moreover, the greater the influence of a parameter on the temperature, the greater the interaction with other parameters. Therefore, when analyzing the temperature field of embankment dams, the hydraulic conductivity $\left(K_{s}\right)$ and the specific heat capacity $\left(c_{s}\right)$ of the soil should be taken as the key parameters. These two parameters can be determined through an inverse estimation study, and the other parameters with lower sensitivity can be simplified considering proper assumptions.

(3) Each parameter can have both favorable and unfavorable impacts on temperature values. Results show that the hydraulic conductivity $\left(K_{s}\right)$ has a favorable influence on the temperature values, while, depending on the position, the soil density $\left(\rho_{s}\right)$, its thermal conductivity $(\lambda)$, and the soil specific heat capacity $\left(c_{s}\right)$ have both favorable and unfavorable effects on the temperature. These impacts can provide valuable information for hydrothermal coupling model correction of embankment dams.

\section{Data Availability}

The data used to support the findings of this study are available from the corresponding author upon request.

\section{Conflicts of Interest}

The authors declare that there are no conflicts of interest regarding the publication of this paper.

\section{Acknowledgments}

This work was supported by the National Natural Science Foundation of China (Grant no. 51679194) and Open Research Fund of Key Laboratory of Failure Mechanism and Safety Control Techniques of Earth-Rock Dam of the Ministry of Water Resources (Grant no. YK319011).

\section{References}

[1] C. R. Song and T. Y. Yosef, "Seepage monitoring of an embankment dam based on hydro-thermal coupled analysis," Journal of Engineering Materials and Technology, vol. 139, no. 2, Article ID 021024, 9 pages, 2017.

[2] H. Su, S. Tian, S. Cui, M. Yang, Z. Wen, and W. Xie, "Distributed optical fiber-based theoretical and empirical methods monitoring hydraulic engineering subjected to seepage velocity," Optical Fiber Technology, vol. 31, pp. 111-125, 2016.

[3] A. N. Alekseevich and A. A. Sergeevich, "Numerical Modelling of tailings dam thermal-seepage regime considering phase transitions," Modelling and Simulation in Engineering, vol. 2017, Article ID 7245413, 10 pages, 2017.

[4] T. Y. Yosef, C. R. Song, and K.-T. Chang, "Hydro-thermal coupled analysis for health monitoring of embankment dams," Acta Geotechnica, vol. 13, no. 2, pp. 447-455, 2018.

[5] T. Qin, H. Wang, G. Wang, Y. Liu, and X. Li, "Heterogeneous influence on hydro-thermal behaviors within the core of an embankment dam," Geotechnical and Geological Engineering, vol. 35, no. 5, pp. 2277-2290, 2017.

[6] H. Su, J. Hu, and M. Yang, "Dam seepage monitoring based on distributed optical fiber temperature system," IEEE Sensors Journal, vol. 15, no. 1, pp. 9-13, 2015.

[7] I. M. Sobol, "Sensitivity estimates for nonlinear mathematical models," Mathematical Modelling and Computational Experiment, vol. 1, no. 4, pp. 407-414, 1993.

[8] B. Sudret, "Global sensitivity analysis using polynomial chaos expansions," Reliability Engineering \& System Safety, vol. 93, no. 7, pp. 964-979, 2008.

[9] O. Klepper, "Multivariate aspects of model uncertainty analysis: Tools for sensitivity analysis and calibration," Ecological Modelling, vol. 101, no. 1, pp. 1-13, 1997.

[10] O. Rakovec, M. C. Hill, M. P. Clark, A. H. Weerts, A. J. Teuling, and R. Uijlenhoet, "Distributed evaluation of local sensitivity analysis (DELSA), with application to hydrologic models," Water Resources Research, vol. 50, no. 1, pp. 409-426, 2014.

[11] B. Iooss and P. Lemaître, "A review on global sensitivity analysis methods," Operations Research/Computer Science Interfaces Series, vol. 59, pp. 101-122, 2015.

[12] Y. Wang, J. Ren, S. Hu, and D. Feng, "Global sensitivity analysis to assess salt precipitation for $\mathrm{CO}_{2}$ geological storage in deep saline aquifers," Geofluids, vol. 2017, Article ID 5603923, 16 pages, 2017.

[13] M. D. Mckay, R. J. Beckman, and W. J. Conover, "A comparison of three methods for selecting values of input variables in the analysis of output from a computer code," Technometrics, vol. 42 , no. 1, pp. 55-61, 2000.

[14] R. I. Cukier, C. M. Fortuin, K. E. Shuler, A. G. Petschek, and J. H. Schaibly, "Study of the sensitivity of coupled reaction systems to uncertainties in rate coefficients. I Theory," The Journal of Chemical Physics, vol. 59, no. 8, pp. 3873-3878, 1973. 
[15] M. D. Morris, "Factorial sampling plans for preliminary computational experiments," Technometrics, vol. 33, no. 2, pp. 161-174, 1991.

[16] F. Campolongo, S. Tarantola, and A. Saltelli, "Tackling quantitatively large dimensionality problems," Computer Physics Communications, vol. 117, no. 1, pp. 75-85, 1999.

[17] D. M. King and B. J. C. Perera, "Morris method of sensitivity analysis applied to assess the importance of input variables on urban water supply yield - A case study," Journal of Hydrology, vol. 477, pp. 17-32, 2013.

[18] D. Garcia Sanchez, B. Lacarrière, M. Musy, and B. Bourges, "Application of sensitivity analysis in building energy simulations: Combining first- and second-order elementary effects methods," Energy and Buildings, vol. 68, no. C, pp. 741-750, 2014.

[19] X. Yi, R. Zou, and H. Guo, "Global sensitivity analysis of a threedimensional nutrients-algae dynamic model for a large shallow lake," Ecological Modelling, vol. 327, pp. 74-84, 2016.

[20] Z. Wang, Y. Liu, G. Zhang et al., "Sensitivity analysis of temperature control parameters and study of the simultaneous cooling zone during dam construction in high-altitude regions," Mathematical Problems in Engineering, vol. 2015, Article ID 528589, 12 pages, 2015.

[21] H. Zhang, J. Chen, Z. Wu, Y. Li, and Y. Wu, “Temperature control three-dimensional simulation sensitivity analysis of RCC dam during construction time in cool spell region," in Proceedings of the 2nd International Conference on Multimedia Technology, ICMT 2011, pp. 1277-1281, Hangzhou, China, July 2011.

[22] L. A. Richards, "Capillary conduction of liquids through porous mediums," Journal of Applied Physics, vol. 1, no. 5, pp. 318-333, 1931.

[23] K. L. Kipp, "HST3D; a computer code for simulation of heat and solute transport in three-dimensional ground-water flow systems," USGS Water-Resources Investigations Report 864095, 1987.

[24] M. T. van Genuchten, "A closed-form equation for predicting the hydraulic conductivity of unsaturated soils," Soil Science Society of America Journal, vol. 44, no. 5, pp. 892-898, 1980.

[25] R. W. Healy and A. D. Ronan, "Documentation of computer program VS2Dh for simulation of energy transport in variably saturated porous media; modification of the US Geological Survey's computer program VS2DT,' USGS Water-Resources Investigations Report 96-4230, 1996.

[26] S. Lu, T. Ren, Y. Gong, and R. Horton, "An improved model for predicting soil thermal conductivity from water content at room temperature," Soil Science Society of America Journal, vol. 71, no. 1, pp. 8-14, 2007.

[27] A. Saltelli, M. Ratto, T. Andres et al., Global Sensitivity Analysis: The Primer, Wiley, Chichester, UK, 2008.

[28] F. Campolongo, J. Cariboni, and A. Saltelli, "An effective screening design for sensitivity analysis of large models," Environmental Modeling and Software, vol. 22, no. 10, pp. 1509-1518, 2007.

[29] Q. Ge and M. Menendez, "Extending Morris method for qualitative global sensitivity analysis of models with dependent inputs," Reliability Engineering \& System Safety, vol. 162, pp. 2839, 2017.

[30] I. N. Hamdhan and B. G. Clarke, "Determination of thermal conductivity of coarse and fine sand soils," in Proceedings of the 2010 World Geothermal Congress, pp. 1-7, Bali, Indonesia, 2010.
[31] Z.-W. Wu and H.-Z. Song, "Numerical simulation of embankment dam seepage monitoring with temperature based on thermal-hydro coupling model," Rock and Soil Mechanics, vol. 36, no. 2, pp. 584-590, 2015 (Chinese).

[32] R. F. Carsel and R. S. Parrish, "Developing joint probability distributions of soil water retention characteristics," Water Resources Research, vol. 24, no. 5, pp. 755-769, 1988.

[33] Geotechdata info, "Soil void ratio, 2019," http://www.geotechdata .info/parameter/void-ratio.html. 


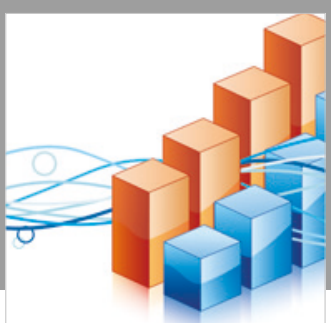

Advances in

Operations Research

\section{-n-m}
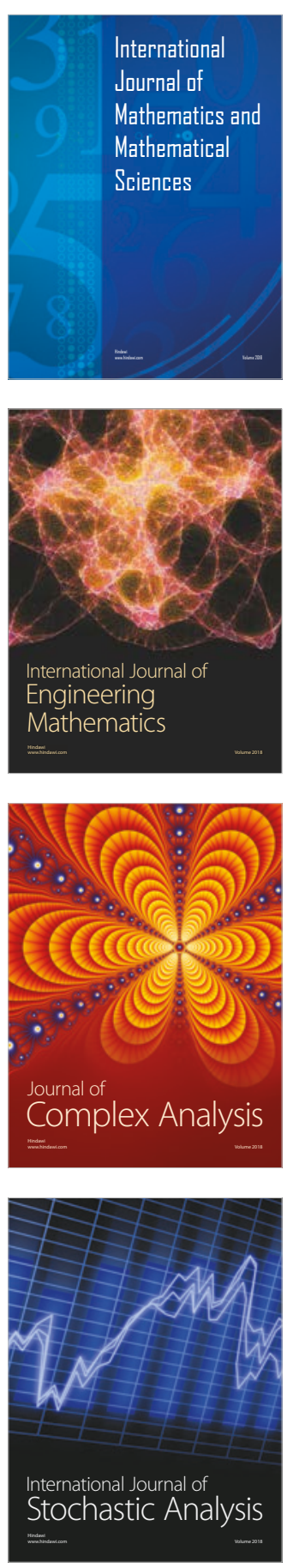
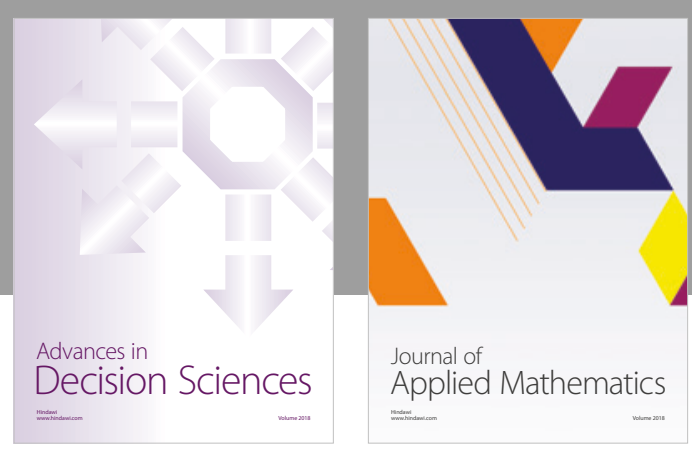

Journal of

Applied Mathematics
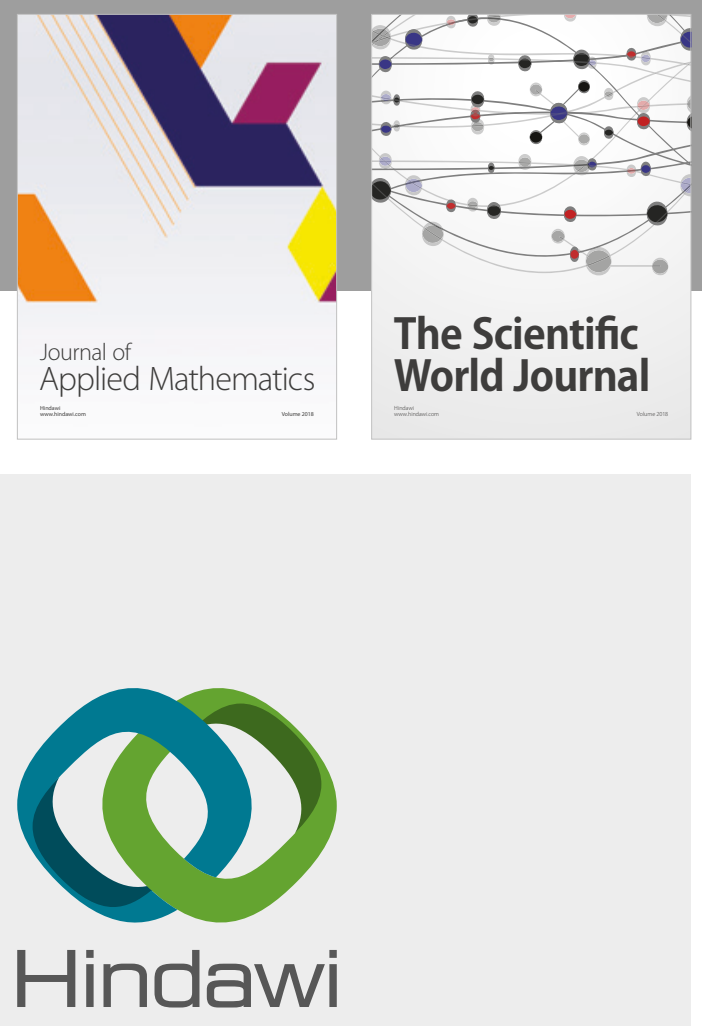

Submit your manuscripts at

www.hindawi.com

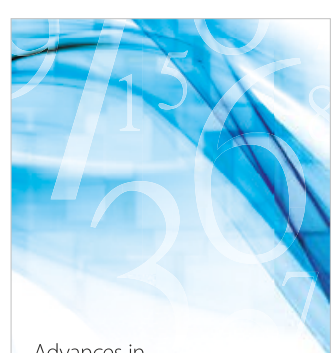

Advances in
Numerical Analysis
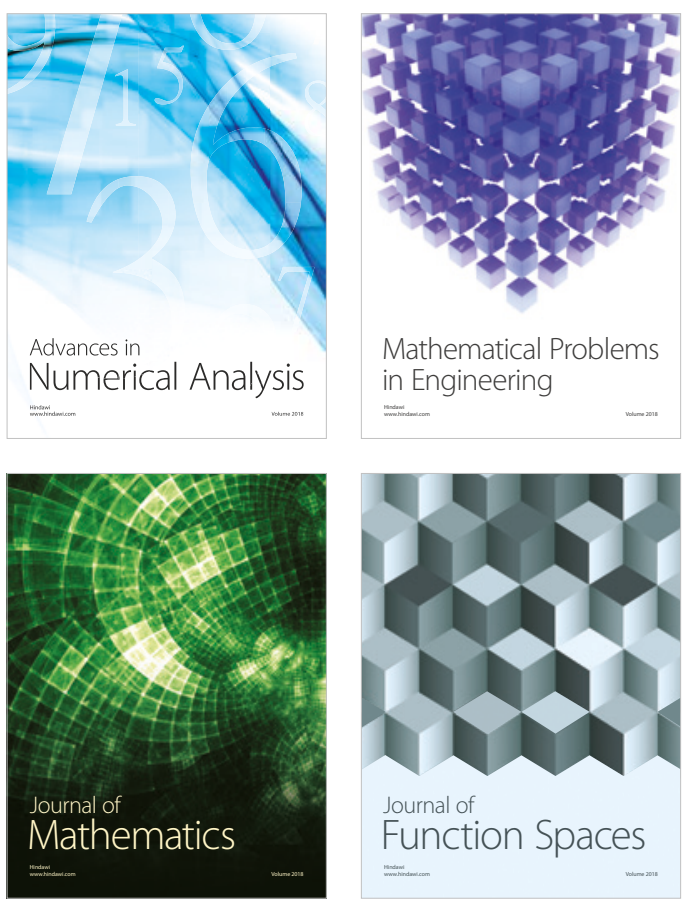

Mathematical Problems in Engineering

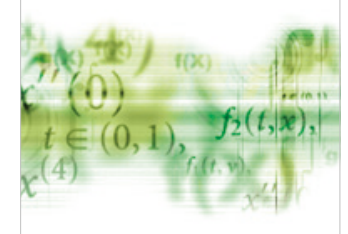

International Journal of

Differential Equations

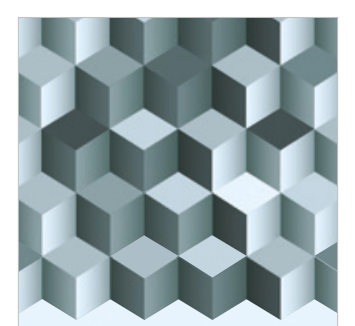

Journal of

Function Spaces

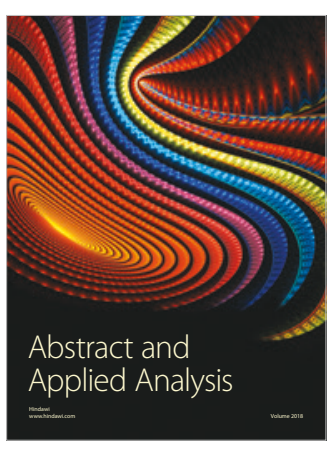

The Scientific

World Journal

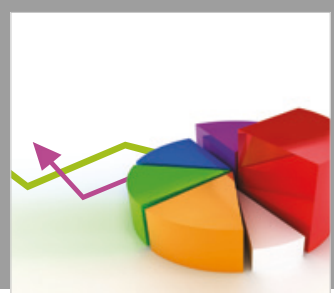

Journal of

Probability and Statistics
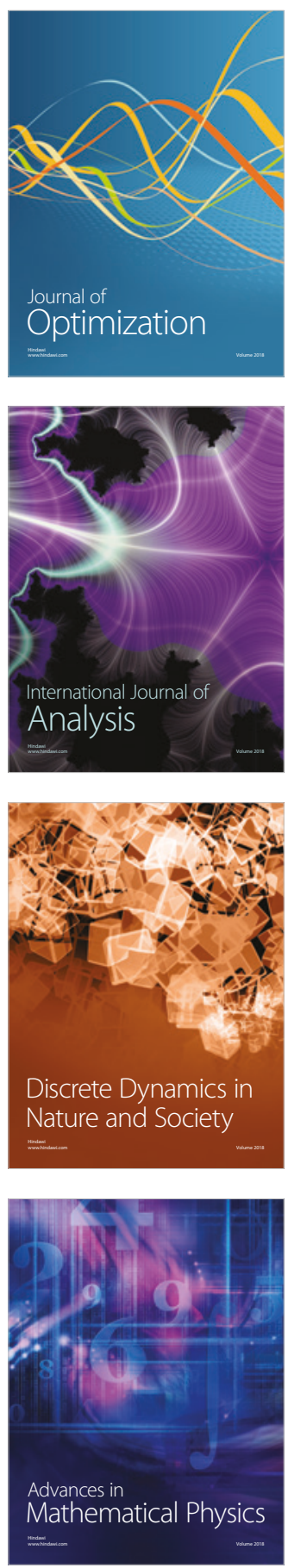